This document is the Accepted Manuscript version of a Published Work that appeared in final form in Applied Materials \& Interfaces, (C) 2017 American Chemical Society after peer review and technical editing by publisher. To access the final edited and published work see Liang, H., Lin, F., Zhang, Z., Liu, B., Jiang, S., Yuan, Q., \& Liu, J. (2017). Multicopper Laccase Mimicking Nanozymes with Nucleotides as Ligands. Acs Applied Materials \& Interfaces, 9(2), 1352-1360. https://doi.org/10.1021/acsami.6b15124

\title{
Multi-copper Laccase Mimicking Nanozymes with Nucleotides as Ligands
}

Hao Liang, ${ }^{a} *$ Feifei Lin, ${ }^{\text {a }}$ Zijie Zhang, ${ }^{\mathrm{b}}$ Biwu Liu, ${ }^{\mathrm{b}}$ Shuhui Jiang, ${ }^{\mathrm{a}}$ Qipeng Yuan, ${ }^{\mathrm{a}}$ and Juewen

$$
\operatorname{Liu}^{\mathrm{b} *}
$$

a. State key Laboratory of Chemical Resource Engineering, Beijing University of Chemical Technology, Beijing, China.

E-mail: lianghao@mail.buct.edu.cn

b. Department of Chemistry and Waterloo, Institute for Nanotechnology, University of

Waterloo, Waterloo, Canada.

E-mail: liujw@uwaterloo.ca

Fax: (+1) 519-7460435; Tel: (+1) 519-8884567 ext. 38919 


\section{Abstract}

Using nanomaterials to achieve functional enzyme mimics (nanozymes) is attractive for both applied and fundamental research. Laccases are multi-copper oxidases highly important for biotechnology and environmental remediation. In this work, we report an exceptionally simple yet functional laccase mimic based on guanosine monophosphate (GMP) coordinated copper. It forms an amorphous metal-organic framework (MOF) material. The ratio of copper and GMP is 3:4 as determined by isothermal titration calorimetry. It has excellent laccase-like activity and converts a diverse range of phenol containing substrates such as hydroquinone, naphthol, catechol and epinephrine. Comparative work shows that the activity is originated from guanosine coordination instead of phosphate binding in GMP. $\mathrm{Cu}^{2+}$ is required and cannot be substituted by other metal ions. At the same mass concentration, the Cu/GMP nanozyme has a higher $V_{\max }$ and similar $K_{\mathrm{m}}$ compared to the protein laccase. To achieve the same catalytic efficiency, the cost of the Gu/GMP is $~ 2400$-fold lower than that of laccase. The $\mathrm{Cu} / \mathrm{GMP}$ is much more stable at extreme $\mathrm{pH}$, high salt, high temperature and for long-term storage. This is one of the first laccase-mimicking nanozymes, which will find important applications in analytical chemistry, environmental protection, and biotechnology.

Keywords: laccase; metal-organic frameworks; nucleotides; copper; nanozymes 


\section{Introduction}

Laccases are a family of copper-containing oxidases that oxidize a broad range of biologically and environmentally important substrates such as polyphenols, polyamines, and aryl diamines. ${ }^{1-3}$ In these reactions, dioxygen is converted to water without the production or need of hydrogen peroxide, making laccases a green catalyst. Current production of laccases relies on fermentation with a low yield and a high cost. Laccase also suffer from poor stability.

To solve these problems, efforts have been made to mimic laccases using various copper ligands, such as porphyrins, ${ }^{4-5}$ phthalocyanine, ${ }^{6-7}$ and imidazole.${ }^{8-10}$ However, most of these complexes contain only one or two copper ions, while natural laccases have four. ${ }^{3,11}$ Nanoparticle-based enzyme mimics known as nanozymes are attractive due to their low cost and high stability. ${ }^{12-14} \mathrm{~A}$ few interesting examples are known, such as gold nanoparticle mimicking glucose oxidase, ${ }^{15-18}$ nanoceria mimicking oxidase, catalase, and superoxide dismutase, ${ }^{19-20}$ and iron oxide nanoparticles mimicking peroxidase. ${ }^{21-25}$ Recently, a laccase mimic was reported using copper containing carbon dots. ${ }^{26}$ However, the coordination environment is difficult to study in such a complex system.

Metal-organic frameworks (MOFs) refer to metal coordinated infinite porous organic structures. ${ }^{27-30}$ While most MOFs are crystalline, amorphous MOFs are also known. ${ }^{31}$ A few MOF-based nanozymes (MOFzymes) have been reported, ${ }^{32-38}$ but none of them showed the laccase activity. Nucleotides are highly versatile metal ligands, ${ }^{39-43}$ and they can also produce MOFs. ${ }^{44-45}$ When dispersed in water, these MOFs either exist as nanoparticles, ${ }^{45-48}$ or swell to form hydrogels. ${ }^{49-51}$ We recently observed peroxidase-like activity with adenosine 
monophosphate (AMP) coordinated $\mathrm{Fe}^{3+}$ nanoparticles. Although nucleotide-coordinated $\mathrm{Cu}^{2+}$ was also prepared, ${ }^{42,52-54}$ their laccase activity has yet to be studied. We reason that such multi-copper coordination environment might be an ideal laccase mimic, and its excellent performance is indeed demonstrated in this work.

\section{Materials and Methods}

Chemicals. Guanosine, guanosine 5'-monophosphate (GMP) disodium salt hydrate, adenosine 5'-monophosphate (AMP) disodium salt, and cytidine 5'-monophosphate (CMP) disodium salt, 2,4-dichlorophenol (2,4-DP), 4-aminoantipyrine (4-AP), 4-(2-hydroxyethyl)-1-piperazineethanesulfonic acid (HEPES), and all the metal chloride salts were from Aladdin Inc.(Shanghai,China). Laccase and guanosine-5'-triphosphoric acid (GTP) disodium salt were from Yuanye Biotechnology Co., Ltd (Shanghai,China). 2-(N-morpholino) ethanesulfonic acid (MES)monohydrate was from Sinopharm Chemical Reagent Co.,Ltd (Shanghai,China). Milli-Q water was used to prepare all the buffers and solutions.

Preparation of $\mathbf{C u} /$ nucleotide MOFs. The MOFs were prepared by first mixing a nucleotide

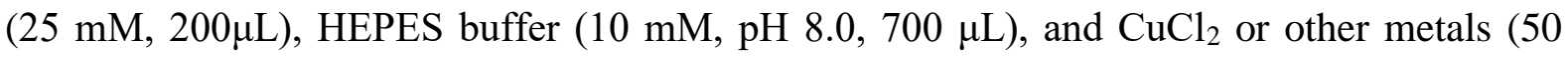
$\mathrm{mM}, 100 \mu \mathrm{L}$ ). The solution was then centrifuged at 10,000 rpm for $5 \mathrm{~min}$, and the precipitant was washed with Milli-Q water three times. Other conditions were also tested such as in water without buffer as control experiments.

Characterization of $\mathbf{C u} /$ nucleotide MOFs. The above prepared precipitant was lyophilized to obtain solid powders for X-ray diffraction (XRD) and Fourier transform infrared spectroscopy (FTIR) analysis. XRD was performed on an X-ray diffractometer (Bruker, 
Germany) using Cu-Ka radiation $(\lambda=1.5178 \AA$, $40 \mathrm{kV} \times 40 \mathrm{~mA})$. The $2 \theta$ was scanned from $10^{\circ}$ to $70^{\circ}$ at $0.1^{\circ} \mathrm{s}^{-1}$. FTIR was performed on a Nicolet Model 205 spectrometer. Transmission electron microscopy (TEM) was performed on a Hitachi H-800 transmission electron microscope after drying an aqueous disperse of the MOF on a 230 mesh holy carbon copper grid. Scanning electron microscopy (SEM) was performed on a Hitachi S-4700 microscope. Dynamic light scattering (DLS) measurement (Zetasizer Nano 90, Malvern) was used to measure the particle size and $\zeta$-potential at $25^{\circ} \mathrm{C}$ with a MOF concentration of 0.1 $\mathrm{mg} / \mathrm{mL}$ in MES buffer (30 mM, pH 6.8). X-ray photoelectron spectroscopy (XPS) was carried out on an XPS spectrometer (Kratos Axis Supra) with a monochromatic Al Ka (hv = 1486.6 eV) source. The lyophilized samples were spread evenly on a conductive adhesive, covered with an aluminum foil, and pressed before measurement. Nitrogen adsorption/desorption isotherms were obtained using a QUantachrome Autosorb-1 system at $77 \mathrm{~K}$.

ITC. ITC was performed using a VP-ITC Microcalorimeter (MicroCal). Prior to each measurement, all the solutions were degassed to remove air bubbles. GMP (1 mM) in water was loaded in the $1.45 \mathrm{~mL}$ ITC cell at $25{ }^{\circ} \mathrm{C}$. In a syringe of $280 \mu \mathrm{L}, \mathrm{CuCl}_{2}(10 \mathrm{mM})$ in the Milli-Q was titrated into the cell (10 $\mu \mathrm{L}$ each time, except for the first injection with $2 \mu \mathrm{L})$.

Catalytic activity assays. The catalytic performance was measured by the chromogenic reaction of phenolic compounds with 4-AP. First, 4-AP $(1 \mathrm{mg} / \mathrm{mL}, 100 \mu \mathrm{L})$ and 2,4-DP $(1 \mathrm{mg} / \mathrm{mL}, 100 \mu \mathrm{L})$ solutions were mixed with MES buffer $(30 \mathrm{mM}, \mathrm{pH}$ 6.8, $700 \mu \mathrm{L})$. Then a catalyst $(1 \mathrm{mg} / \mathrm{mL}, 100 \mu \mathrm{L})$ was added. After $1 \mathrm{~h}$, the mixture was centrifuged at 10,000 rpm for $2 \mathrm{~min}$. The absorbance of the supernatant at $510 \mathrm{~nm}$ was measured. The other substrates (phenol, hydroquinone, naphthol and catechol) were dissolved at $100 \mu \mathrm{g} / \mathrm{mL}$ in MES buffer 
(30mM, pH 6.8) containing $100 \mu \mathrm{g} / \mathrm{mL} 4-\mathrm{AP}$ and assayed in the same way.

Determination of enzyme kinetic parameters. Various concentrations of 2,4-DP (10, 20, 40, $60,80,100 \mu \mathrm{g} / \mathrm{mL}$ ) were respectively reacted with $0.1 \mathrm{mg} / \mathrm{mL} \mathrm{Cu} / \mathrm{GMP}$ or laccase to measure the initial reaction rate. In all these reactions, the concentration of 4-AP was in excess at $1 \mathrm{mg} / \mathrm{mL}$. The kinetic parameters $\left(K_{\mathrm{m}}\right.$ and $\left.V_{\max }\right)$ were calculated by the Michaelis-Menten equation $1 / V_{0}=K_{\mathrm{m}} / V_{\max } \cdot 1 /\left[S_{0}\right]+1 / V_{\max }$.

Stability comparison. To study the effect of $\mathrm{pH}$, laccase and $\mathrm{Cu} / \mathrm{GMP}$ were separately incubated in a variety of pH's (3.0-9.0) for $8 \mathrm{~h}$ before the activity assay. The relative activity is compared with that at $\mathrm{pH}$ 6.8. The effect of temperature was measured by storing laccase and $\mathrm{Cu} / \mathrm{GMP}$ at $30-90{ }^{\circ} \mathrm{C}$ for $30 \mathrm{~min}$, and the activity at $30^{\circ} \mathrm{C}$ was taken as a reference. The effect of ionic strength was measured by incubating laccase or $\mathrm{Cu} / \mathrm{GMP}$ in different concentrations of $\mathrm{NaCl}(0,150,300$ and $500 \mathrm{mM})$. For all these studies, $1 \mathrm{~h}$ of the enzyme reaction was allowed before the absorbance of the supernatant at $510 \mathrm{~nm}$ was measured. The long-term storage stability was measured daily for the residual activity of laccase or $\mathrm{Cu} / \mathrm{GMP}$ CPs dispersed in ultrapure water stored at room temperature.

Reaction with epinephrine. A $50 \mu \mathrm{L}$ of epinephrine sample $(100 \mu \mathrm{g} / \mathrm{mL})$ dissolved in 12 $\mathrm{mM} \mathrm{HCl}$ was mixed with a catalyst $(1 \mathrm{mg} / \mathrm{mL}, 100 \mu \mathrm{L})$ and $\mathrm{MES}$ buffer $(50 \mathrm{mM}, \mathrm{pH} 6.8,850$ $\mu \mathrm{L})$. The oxidation of epinephrine was monitored at $485 \mathrm{~nm}$. To measure the detection limit, different concentrations of epinephrine were respectively mixed with $0.1 \mathrm{mg} / \mathrm{mL}$ catalyst in the same buffer for $1 \mathrm{~h}$ at room temperature before absorption measurement. The limit of detection was calculated by $3 \sigma / b$, where $\sigma$ is the standard deviation of the blank signals, and $b$ is the slope of the regression line. 


\section{Results and Discussion}

Cu/GMP nanozyme with laccase-like activity. Nucleotides are excellent metal ligands. A scheme of GMP reacting with $\mathrm{Cu}^{2+}$ is show in Figure 1A, where both the nucleobase and the phosphate might contribute to coordination. To test the feasibility of using such nucleotide-coordinated copper as a laccase mimic, we used 2,4-dichlorophenol (2,4-DP) as the substrate together with 4-aminoantipyrine (4-AP) (Figure 1B). ${ }^{55}$ Each compound alone has no absorption in the visible region (Figure 1C). 2,4-DP is the real substrate and its laccase oxidation product reacts with 4-AP to produce a red adduct with an absorption peak at 510 nm (Figure 1C and inset).
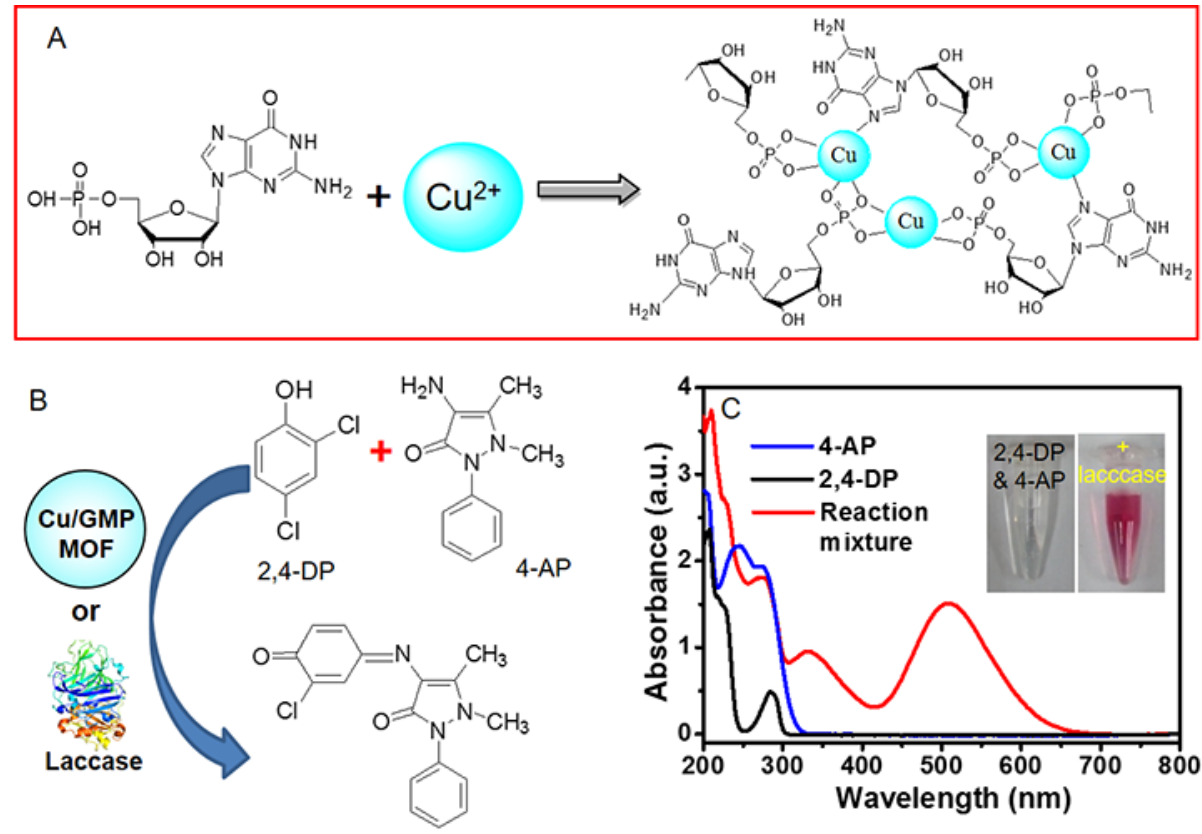

Figure 1. (A) A scheme of $\mathrm{Cu}^{2+}$ reacting with GMP to form the MOFzyme. (B) The reaction of 2,4-DP and 4-AP catalyzed by $\mathrm{Cu} / \mathrm{GMP}$ or laccase. (C) UV-vis spectra of the two substrates and their reaction product in the presence of laccase (Inset: $0.1 \mathrm{mg} / \mathrm{mL}$ of 2,4-DP and 4-AP in $\mathrm{pH}$ 6.8 MES buffer before and after oxidation with $0.1 \mathrm{mg} / \mathrm{mL}$ of laccase). 
Before starting systematic work, a control experiment was performed to react free $\mathrm{Cu}^{2+}$ with the substrates in water, and a light pink color was produced (Figure 2A). This indicates that $\mathrm{Cu}^{2+}$ alone has a moderate activity. The $\mathrm{Cu}^{2+} / \mathrm{GMP}$ mixture, however, produced a much stronger color. Since the $\mathrm{Cu}^{2+} / \mathrm{GMP}$ mixture forms nanoparticles (vide infra), the amount of exposed copper centers is much less compared to the total $\mathrm{Cu}^{2+}$ in the sample. Therefore, the activity of copper is drastically increased by complexing with GMP. We next measured the activity of the $\mathrm{Cu}^{2+} / \mathrm{GMP}$ mixture at different $\mathrm{pH}$ and the activity was quite constant until reaching the basic $\mathrm{pH}$, where activity started to drop (Figure $2 \mathrm{~B}$ ). We decided to use $\mathrm{pH} 6.8$ in this work since protein laccase also has good activity at this $\mathrm{pH}$ (vide infra), facilitating comparison.

To further confirm the laccase-like activity is from the MOF, another control experiment was designed (Figure 2D). The $\mathrm{Cu} / \mathrm{GMP}$ mixture was filtered, and the filtered clear solution had almost no activity, while the precipitants on the filter membrane were active. This also indicates that the activity is indeed from the MOF instead of the free soluble $\mathrm{Cu}^{2+}$ containing species. 


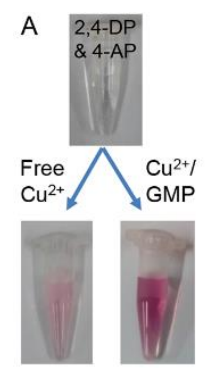

D

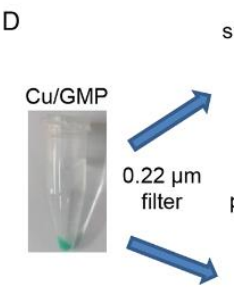

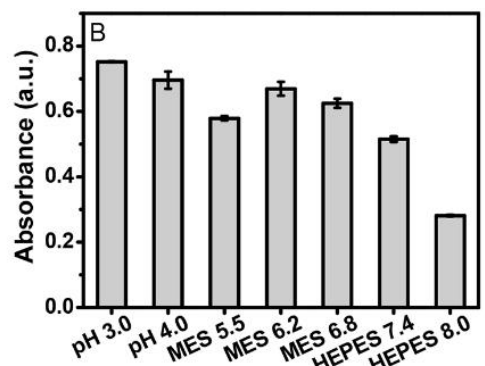

supernatant

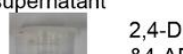
$\stackrel{\text { 2,4-DP }}{\stackrel{\text { \&4-AP }}{\longrightarrow}}$
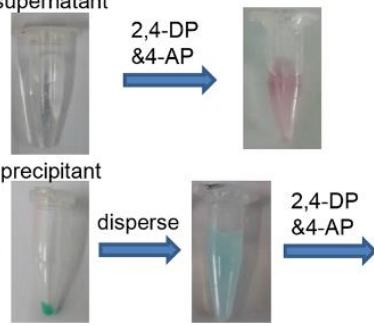

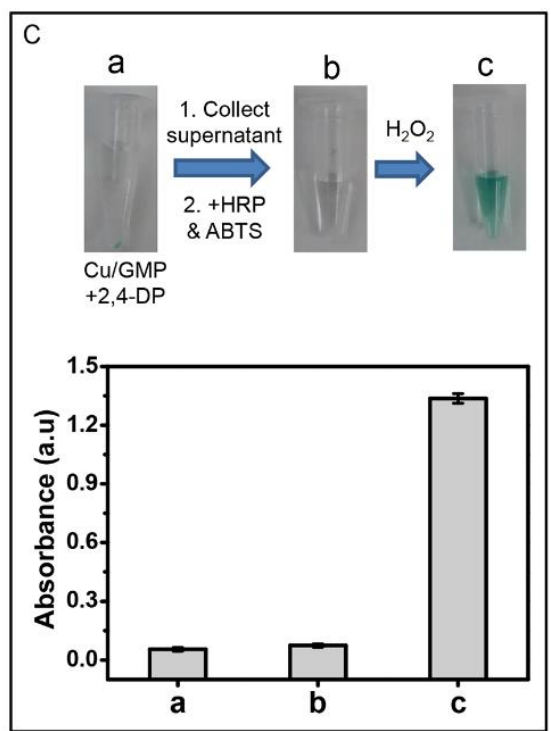

Figure 2. (A) A control experiment comparing free $\mathrm{Cu}^{2+}$ and its mixture with GMP for laccase-like activity in water. (B) $\mathrm{pH}$-dependent activity of the $\mathrm{Cu} / \mathrm{GMP}$ MOF by monitoring the product absorbance at $510 \mathrm{~nm}$. (C) A control experiment testing the activity of the precipitated MOF and the supernatant. (D) Photographs of (a) Cu/GMP reacted with 2,4-DP in pH 6.8 MES buffer after centrifugation, (b) the supernatant with ABTS and HRP added after centrifugation, and (c) after adding $\mathrm{H}_{2} \mathrm{O}_{2}$ to (b).The UV-vis absorbance at $414 \mathrm{~nm}$ of the samples is also shown.

By definition, laccase directly converts $\mathrm{O}_{2}$ to water without producing $\mathrm{H}_{2} \mathrm{O}_{2}$. In contrast, some other oxidases, such as glucose oxidase, produce $\mathrm{H}_{2} \mathrm{O}_{2}$. To test whether $\mathrm{H}_{2} \mathrm{O}_{2}$ is generated by the $\mathrm{Cu} / \mathrm{GMP}$ catalyzed reaction, we centrifuged the reaction mixture of 2,4-DP and $\mathrm{Cu} / \mathrm{GMP}$ (4-AP was omitted to avoid the red color). To this supernatant, ABTS and horseradish peroxidase (HRP) was added, and we failed to observe a color change (inset of Figure 2C), suggesting the lack of $\mathrm{H}_{2} \mathrm{O}_{2}$ in the system. As a positive control, adding $\mathrm{H}_{2} \mathrm{O}_{2}$ resulted in the expected green color from ABTS oxidation. Therefore, $\mathrm{Cu} / \mathrm{GMP}$ is indeed a 
laccase mimic instead of other oxidases that produce $\mathrm{H}_{2} \mathrm{O}_{2}$.

Effect of nucleobase, phosphate, and metal ions on the MOFzyme activity. After confirming the laccase-like activity, we want to understand the chemical reason for catalysis. Three MOFs were prepared by respectively mixing $\mathrm{Cu}^{2+}$ with GMP, AMP, and CMP, yielding a light blue precipitant (Figure 3A, upper tubes). Interestingly, these three samples were all active as indicated by the red color of the reaction product (Figure 3A, lower tubes). $\mathrm{Cu} / \mathrm{GMP}$ has the highest activity, followed by $\mathrm{Cu} / \mathrm{AMP}$ and $\mathrm{Cu} / \mathrm{CMP}$ (see Figure $\mathrm{S} 1$ for quantification). Therefore, we focused the rest of our study on $\mathrm{Cu} / \mathrm{GMP}$.

Since GMP contains a guanosine and a phosphate, we next respectively mixed $\mathrm{Cu}^{2+}$ with these two components (Figure 3A, the last two tubes). In each case, blue precipitants were formed, but the supernatant of the guanosine sample was slightly blue, suggesting that a fraction of $\mathrm{Cu}^{2+}$ remained free. Free inorganic phosphate fully precipitated $\mathrm{Cu}^{2+}$, but its laccase activity was very low. Therefore, the interaction between $\mathrm{Cu}^{2+}$ and guanosine is required for the activity, while the phosphate in GMP only provides additional coordination sites without contributing much to catalysis.

After understanding the ligand requirement, we next tested a few other metal ions, including lanthanides and transition metals. While most of them precipitated with GMP (Figure 3C, upper tubes), little activity was observed (Figure 3C, D). Therefore, copper is critical for the activity, which is the same as natural laccases.

The above complexes were prepared at a molar ratio of $\mathrm{Cu}^{2+}: \mathrm{GMP}=1: 1$. We next varied the ratio by fixing the GMP concentration. The more $\mathrm{Cu}^{2+}$ added, the more precipitated products were obtained (Figure S2). We also measured the activity at four different ratios 
$(\mathrm{Cu}: \mathrm{GMP}=0.25,0.5,0.75$ and 1 , Figure S3). The highest activity was obtained at a ratio of 1:1. It is likely that with more $\mathrm{Cu}^{2+}$ added, the final product has more $\mathrm{Cu}^{2+}$ on the surface, explaining the higher activity.
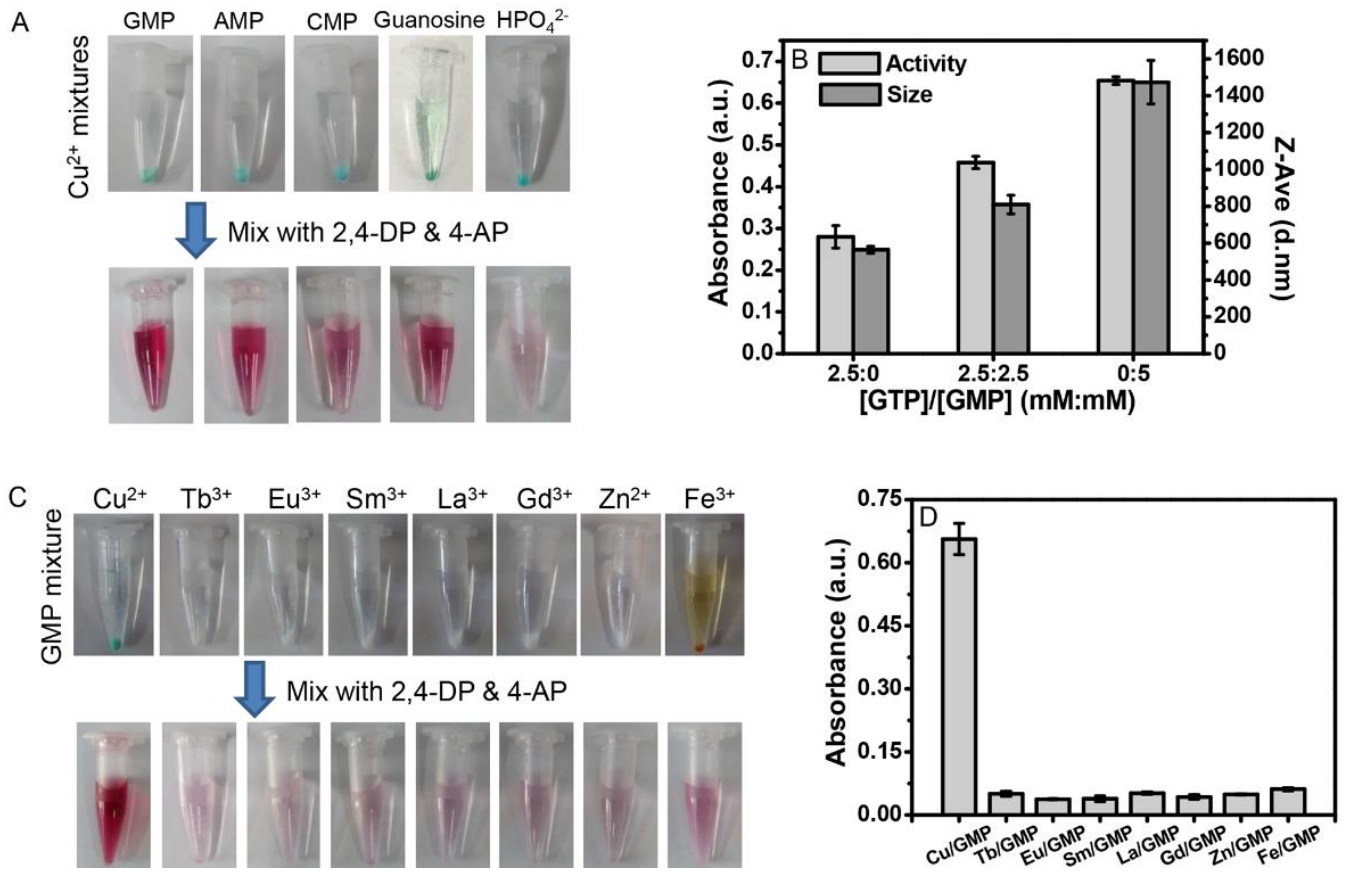

Figure 3. MOF formed by various nucleotides and metal ions and their laccase-mimetic activity. Photographs of MOFs prepared (A) by mixing $\mathrm{Cu}^{2+}$ and various nucleotides, guanosine and inorganic phosphate, and (C) by mixing GMP with various metal ions without and with the substrates. The red color indicates laccase-like activity. (B) The activity of $\mathrm{Cu}^{2+}$ coordinated with GTP/GMP mixture at different ratios and the size of the MOFs. The laccase-like activity was performed by measuring $0.1 \mathrm{mg} / \mathrm{mL}$ of 2,4-DP and 4-AP with metal/nucleotide MOFs $(0.1 \mathrm{mg} / \mathrm{mL})$ in $\mathrm{pH} 6.8 \mathrm{MES}$ buffer. (D) Characterization of the oxidation products using UV-vis spectroscopy in (C). 
Since GMP contains only one phosphate, we also tried GTP with three phosphate groups and thus a higher negative charge density (Figure 3B). This might promote charge repulsion and produce smaller MOFs. While this strategy was successfully applied when for gold coordination with adenine derivatives ${ }^{56}$ the effect on size was not very obvious here. All these samples were above $500 \mathrm{~nm}$, regardless of the GTP content. We measured the zeta-potential of these MOFs, and they all have a value close to zero (Table S1), which may explain that they can all grow to a relatively large size. The GTP sample has lower catalytic activity than the GMP sample. This might be explained by the more favored $\mathrm{Cu}^{2+} /$ phosphate interaction in the GTP sample. From Figure 3A we know that copper phosphate has little activity. Overall, the $\mathrm{Cu}^{2+} / \mathrm{GMP} \mathrm{MOF}$ has the highest activity and was used for subsequent studies.

Characterization of the MOFzyme. Our above DLS measurement already indicated that this $\mathrm{Cu} / \mathrm{GMP}$ MOFzyme has micrometer sizes (Table S1). To characterize its nanostructure, it was examined by SEM (Figure 4A) and TEM (Figure 4B). Large network structures extending over $1 \mu \mathrm{m}$ were observed, consistent with its tendency to precipitate in water. Although the overall materials size has exceeded $1 \mu \mathrm{m}$, the features responsible for catalysis are still in the nanometer scale. Its $\zeta$-potential is close to zero, which may explain its aggregation instead of forming dispersed stable nanoparticles. ${ }^{56}$ This sample can be readily dispersed in water by vortex mixing.

The surface area and pore size distribution were measured by nitrogen adsorption and the results were calculated using the Barrett-Joyner-Halenda $(\mathrm{BJH})$ model (Figure 4C). The specific surface area is $7.23 \mathrm{~m}^{2} / \mathrm{g}$, suggesting that the MOF structure has collapsed during 
drying and this might be related to the non-crystalline nature of our materials rendering a low mechanical strength. Indeed, during drying, the volume of the sample decreased significantly and the color of the material turned from blue to black, consistent with collapsing. The dried material still has certain porosity larger than $5 \mathrm{~nm}$ (Figure 4D). Given the small surface area, these pores are likely on the surface of the material.

To understand the thermodynamics and binding stoichiometry, this reaction was also studied using isothermal titration calorimetry (ITC), where $\mathrm{Cu}^{2+}$ was gradually titrated into GMP and the released heat was followed (Figure 4E). The background heat from GMP dilution and from $\mathrm{Cu}^{2+}$ into water was both close to zero (Figure 4F). We integrated the heat and fitted the data to a binding model (Figure $4 \mathrm{G}$ ). The binding of $\mathrm{Cu}^{2+}$ by GMP is quite complex and can be divided into two stages. Initially an endothermic reaction was observed (as indicated by the upward spikes of the thermogram) with a $\mathrm{Cu}^{2+} / \mathrm{GMP}$ ratio of 0.25 , suggesting each $\mathrm{Cu}^{2+}$ is chelated by four GMP molecules. The heat absorption is likely related to the release of water from $\mathrm{Cu}^{2+}$, which increase the entropy of the system. Following that, an exothermic reaction was observed with further increase of $\mathrm{Cu}^{2+}$. In this step, the ratio between $\mathrm{Cu}^{2+}$ and GMP is 0.5 . Therefore, the overall $\mathrm{Cu}^{2+}$-to-GMP ratio is 3:4 in the final product. 

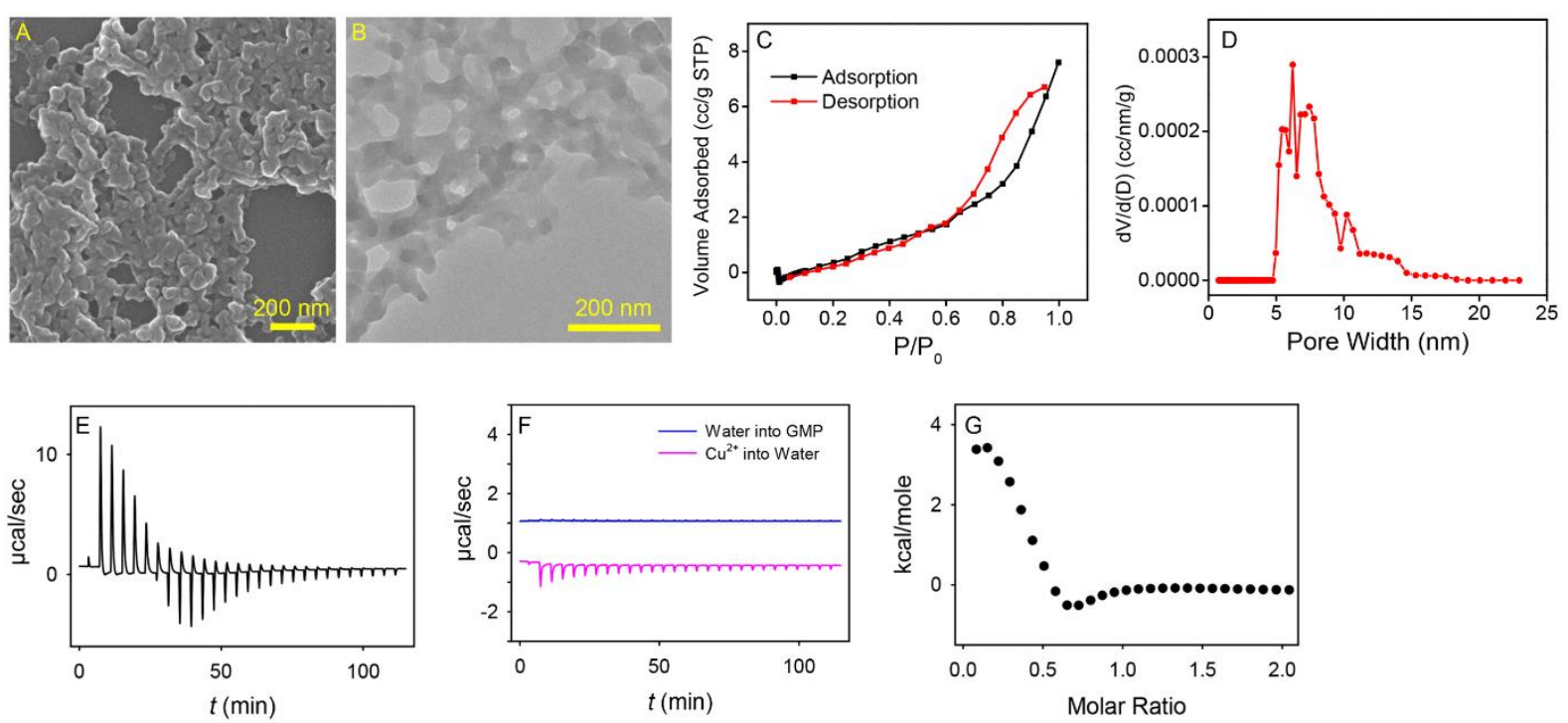

Figure 4. (A) SEM and (B) TEM micrographs of Cu/GMP. (C) Nitrogen adsorption isotherm of the $\mathrm{Cu} / \mathrm{GMP}$ after drying to measure the specific surface area. (D) Pore size distribution of the dried $\mathrm{Cu} / \mathrm{GMP}$ from nitrogen adsorption. The ITC trace of titrating (E) $\mathrm{Cu}^{2+}$ into GMP and (F) blanks of buffer to GMP or $\mathrm{Cu}^{2+}$ into water. $(\mathrm{G})$ The integrated heat of the reaction. The ITC experiment was at $298 \mathrm{~K}$ with $10 \mathrm{mM} \mathrm{CuCl}_{2}$ in water in titrated into $1 \mathrm{mM} \mathrm{GMP}$ in water.

To understand the oxidation state of copper in our $\mathrm{Cu} / \mathrm{GMP}$ MOF, X-ray photoelectron spectroscopy (XPS) was used. The full scan spectrum shows $\mathrm{Cu}, \mathrm{O}, \mathrm{N}, \mathrm{C}$ and P (Figure S4). The peaks at $931.9 \mathrm{eV}$ and $951.8 \mathrm{eV}$ in the high-resolution XPS spectrum (Figure 5A) are assigned to the $\mathrm{Cu} 2 \mathrm{p} 3 / 2$ and $\mathrm{Cu} 2 \mathrm{p} 1 / 2$ electrons of $\mathrm{Cu}^{2+}$, respectively. The lower binding energy peaks at $930.2 \mathrm{eV}$ and $950.1 \mathrm{eV}$ suggest the presence of $\mathrm{Cu}^{+}$or $\mathrm{Cu}^{0}$. Furthermore, the Auger $\mathrm{Cu}$ LMM spectra confirmed the presence of $\mathrm{Cu}^{+}$at $572.9 \mathrm{eV}$ (Figure S5). ${ }^{57-58}$ Therefore, a fraction of $\mathrm{Cu}^{2+}$ is reduced to $\mathrm{Cu}^{+}$during the reaction of forming the $\mathrm{Cu} / \mathrm{GMP}$ MOF. For comparison, we also measured the XPS spectrum of the $\mathrm{Cu} / \mathrm{CMP}$ MOF (Figure 
S6), and the high resolution spectra in the copper region is shown in Figure 5B. Only the $\mathrm{Cu} 2 \mathrm{p} 3 / 2$ and $\mathrm{Cu} 2 \mathrm{p} 1 / 2$ electrons of $\mathrm{Cu}^{2+}$ at $933.2 \mathrm{eV}$ and $952.8 \mathrm{eV}$ were observed, suggesting that no $\mathrm{Cu}^{+}$or $\mathrm{Cu}^{0}$ formed in the $\mathrm{Cu} / \mathrm{CMP}$ complex. The presence of reduced copper species might explain the higher activity of the $\mathrm{Cu} / \mathrm{GMP}$ MOFzyme.

To further understand the binding mechanism of $\mathrm{Cu}$ and GMP, infrared (IR) spectra were collected for the free GMP and Cu/GMP (Figure S7). The peaks of phosphate $\left(976 \mathrm{~cm}^{-1}\right.$ and $\left.1081 \mathrm{~cm}^{-1}\right)$ and $\mathrm{C}-\mathrm{N}$ stretching $\left(1484 \mathrm{~cm}^{-1}\right)$ of GMP shifted after adding $\mathrm{Cu}^{2+}$, indicating that both phosphate and guanosine in GMP are involved in $\mathrm{Cu}^{2+}$ binding. This is consistent with the studies above using free guanosine and phosphate as well as ITC. Finally, X-ray diffraction showed that $\mathrm{Cu} / \mathrm{GMP}$ is non-crystalline, and thus it is an amorphous MOF (Figure S8). ${ }^{31}$ This may be related to the asymmetric chemical structure of nucleotides and high coordination flexibility of copper ions. ${ }^{45}$
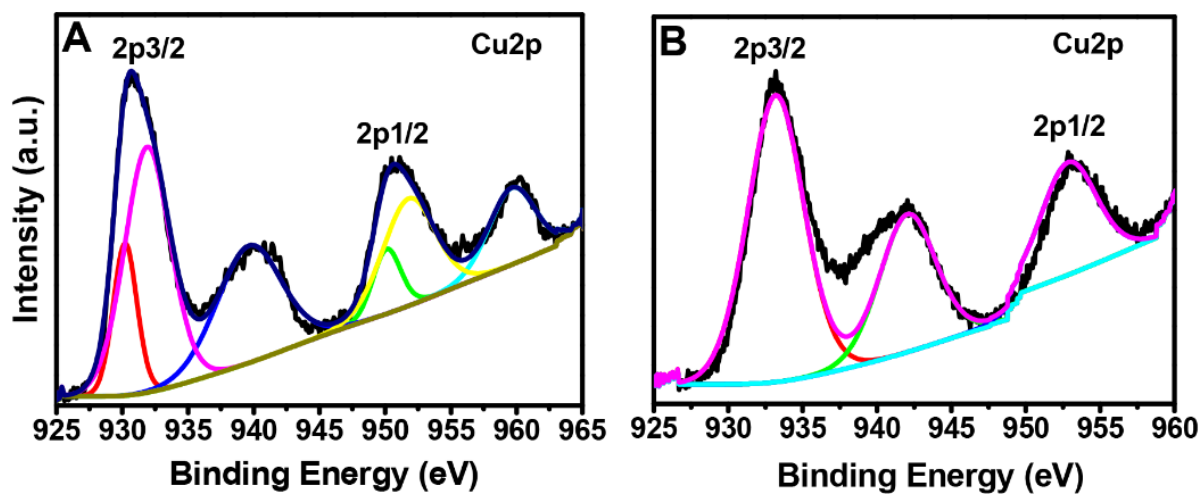

Figure 5. The $\mathrm{Cu} 2 \mathrm{p}$ XPS spectrum of (A) the $\mathrm{Cu} / \mathrm{GMP}(\mathrm{B})$ the $\mathrm{Cu} / \mathrm{CMP} \mathrm{MOF}$.

$\mathrm{Cu} / \mathrm{GMP}$ can rival laccase for activity. Overall, our laccase mimicking $\mathrm{Cu} / \mathrm{GMP}$ is simple to prepare. After characterizing its structure, we next measured its catalytic activity. A 
side-by-side comparison was made with the protein laccase. Higher activity was observed with higher concentration of both protein laccase and the Cu/GMP MOFzyme (Figure 6A). Below $0.1 \mathrm{mg} / \mathrm{mL}, \mathrm{Cu} / \mathrm{GMP}$ was even more active than laccase. Subsequent works were then performed at this concentration.

To extract enzyme kinetic parameters, the reaction kinetics of each catalyst was measured at different substrate concentrations. The $K_{\mathrm{m}}$ and $V_{\max }$ values were calculated by the Michaelis-Menten model, and the results are shown in Figure 6B. The $K_{\mathrm{m}}$ of $\mathrm{Cu} / \mathrm{GMP}$ was nearly the same as that of laccase, indicating that they bind the substrate with a comparable affinity. The $V_{\max }$ of $\mathrm{Cu} / \mathrm{GMP}$ was 5.4 times higher than that of laccase.

The molecular weight laccase is around 80,000 Da. Since each laccase has four copper ions, copper in laccase only accounts for $\sim 0.32 \%$ of its molecular weight. On the other hand, copper is $\sim 20 \%$ of the mass in our $\mathrm{Cu} / \mathrm{GMP}$. Therefore, when normalized to the number of copper centers, the protein laccase is much more active. Based on the SEM, the Cu/GMP MOF exists as aggregated nanoparticles, and only a small fraction of the copper is exposed on the surface. Therefore, further work is needed to quantify the activity of each surface active in this laccase mimic to have a fair comparison with the active center activity. Overall, the activity of this simple laccase mimic is excellent when compared at the same mass concentration with laccase. The excellent activity of $\mathrm{Cu} / \mathrm{GMP}$ is attributable to its multinuclear arrangement of $\mathrm{Cu}^{2+}$, which is similar to laccase and can serve as a good functional mimic.

Cu/GMP is a highly robust laccase mimic. High activity and stability of enzymes are desired for practical applications. ${ }^{59}$ One method to improve enzyme stability is to embed 
them in a matrix. For example, Zare and co-workers encapsulated a few enzymes including laccase in copper phosphate nanoflowers. ${ }^{55} \mathrm{We}$ reason that using a protein-free material such as $\mathrm{Cu} / \mathrm{GMP}$ is even more attractive and cost-effective.

To test the stability aspect of this MOFzyme, $\mathrm{Cu} / \mathrm{GMP}$ and the protein laccase were systematically compared in various harsh conditions. First, they were exposed to a range of buffers from $\mathrm{pH} 3.0$ to 9.0 at room temperature for $8 \mathrm{~h}$. Then, both catalysts were assayed in the typical pH 6.8 reaction buffer (Figure $6 \mathrm{C}$ ). While laccase lost $\sim 70 \%$ of the activity after incubation at $\mathrm{pH} 3, \mathrm{Cu} / \mathrm{GMP}$ retained $>90 \%$ of activity. The effect of high temperature was studied next. After 30 min exposure of the catalysts from 30 to $90{ }^{\circ} \mathrm{C}$ for 30 min (Figure 6D), the activity of laccase progressively decreased with fully lost activity at $90{ }^{\circ} \mathrm{C}$. However, the activity of $\mathrm{Cu} / \mathrm{GMP}$ was not influenced by the thermal treatment.
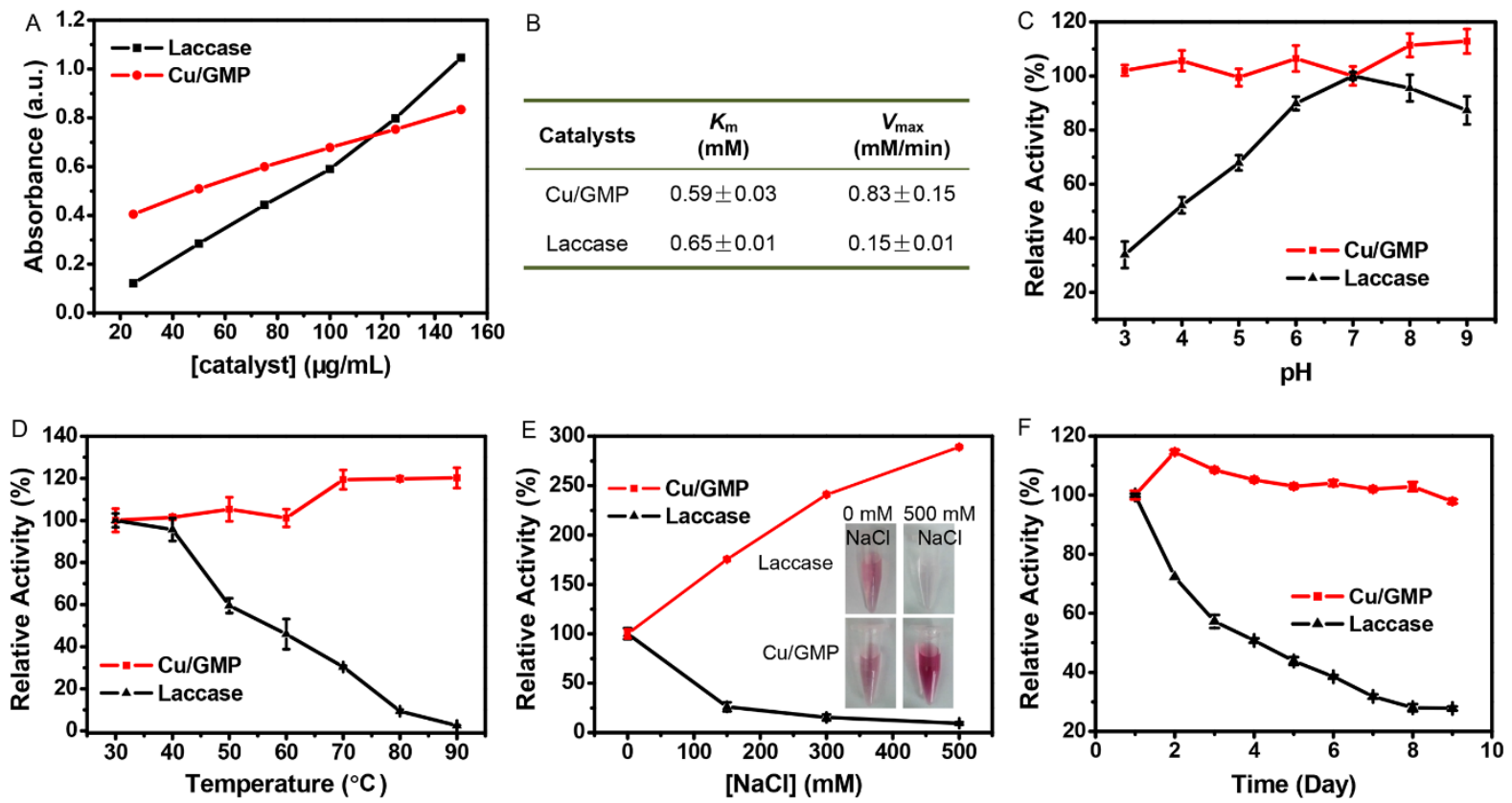

Figure 6. (A) A comparison of the catalytic performance of $\mathrm{Cu} / \mathrm{GMP} \mathrm{MOF}$ and laccase as a function of enzyme concentration. (B) The kinetic parameters for the $\mathrm{Cu} / \mathrm{GMP} \mathrm{MOF}$ and 
laccase. Stability of the $\mathrm{Cu} / \mathrm{GMP}$ MOF compared with the same mass concentration of laccase at different (C) $\mathrm{pH}$, (D) temperature and (E) $\mathrm{NaCl}$ concentration. Inset of (E): photographs of $0.1 \mathrm{mg} / \mathrm{mL}$ of laccase or $\mathrm{Cu} / \mathrm{GMP}$ as the catalysts to convert $0.1 \mathrm{mg} / \mathrm{mL}$ of 2,4-DP at different $\mathrm{NaCl}$ concentrations. (F) A comparison of long-term stability of laccase and $\mathrm{Cu} / \mathrm{GMP}$.

The effect of ionic strength was further tested. The activity of laccase was completely inhibited in high concentration of $\mathrm{NaCl}$ (Figure 6E). High ionic strength might influence the charge distribution and solubility of proteins, which may in turn affect its activity. For $\mathrm{Cu} / \mathrm{GMP}$, it is very interesting that its activity even increased by $\sim 300 \%$ with $500 \mathrm{mM} \mathrm{NaCl}$. High concentration of $\mathrm{NaCl}$ may compete with the substrates for water molecules, thus decreasing the solubility of 2,4-DP and 4-APP (e.g. the salt-out effect). As a result, they might prefer to be adsorbed by the MOFzyme and be converted. We used TEM to observe the $\mathrm{Cu}$ /GMP MOF after exposing in $\mathrm{pH}$, salt and heating (Figure S9). The nanoscale structures were retained after these treatments. It is interesting to note that the $\mathrm{Cu} / \mathrm{GMP}$ in $500 \mathrm{mM} \mathrm{NaCl}$ was better dispersed, which may also explain its high catalytic performance in high ionic strength.

The long-term storage stability is also important for applications. ${ }^{60}$ As shown in Figure $6 \mathrm{~F}, \mathrm{Cu} / \mathrm{GMP}$ retained nearly $100 \%$ of the initial activity after incubated in aqueous solution for 9 days. However, laccase lost more than $70 \%$ of the original activity after the same storage period.

$\mathrm{Cu} / \mathrm{GMP}$ accepts a diverse range of substrates. Laccases can catalyze the oxidation of a 
wide range of substrates. To test the substrate diversity of $\mathrm{Cu} / \mathrm{GMP}$, we next mixed it with four different phenols (Figure 7A). The chemical structures of these phenols are shown in Figure $\mathrm{S} 10 . \mathrm{Cu} / \mathrm{GMP}$ is able to oxidize all of them with a catalytic efficiency significantly better than that of laccase in each case. Especially for naphthol, the activity of the MOFzyme was about 15 times higher than that of laccase. These phenols are important chemicals in industry and they may cause environmental problems. Being able to oxidize them efficiently is highly desirable.

To further demonstrate an environmental application of $\mathrm{Cu} / \mathrm{GMP}$, another substrate was tested. Epinephrine is the main hormone in the adrenal medulla, and is also used to treat anaphylactic shock, bronchial asthma and organic heart disease. Thus, its quantitative analysis is required for diagnosis. We respectively reacted epinephrine with laccase and the Cu/GMP MOF (Figure 7B). A colored oxidation product was observed, indicating the $\mathrm{Cu} / \mathrm{GMP}$ can also convert epinephrine. The absorption spectrum of the final product was measured at $485 \mathrm{~nm}$ (Figure 7C). Figure 7D shows the reaction kinetics with the Cu/GMP MOFzyme is 11-fold faster than that of laccase in the initial $20 \mathrm{~min}$. The kinetic parameters of the MOFzyme and laccase were also calculated (Figure S11), where the $V_{\max }$ of the MOFzyme is $\sim 40$ times higher than that of laccase. 

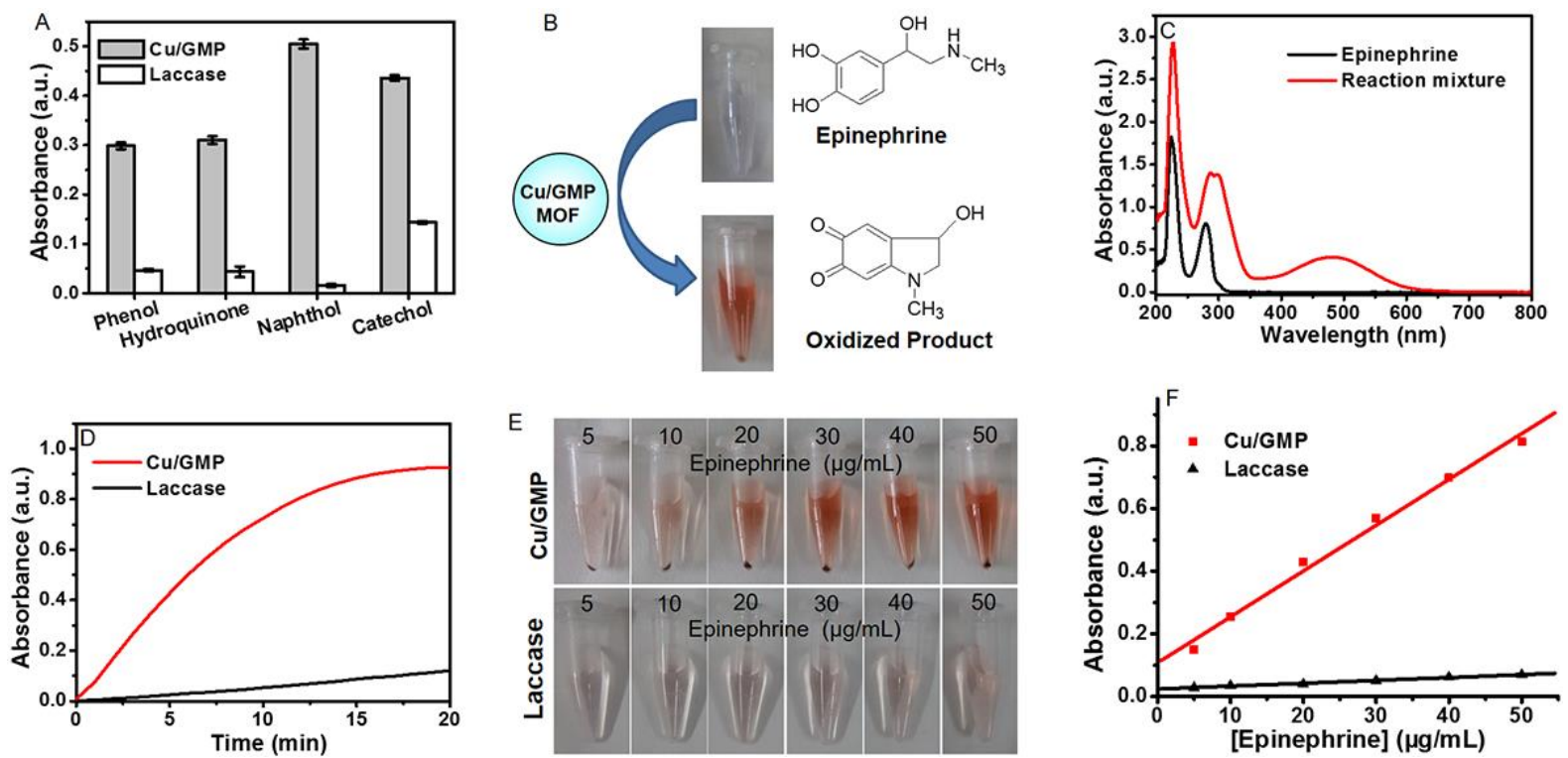

Figure 7. (A) A comparison of the catalytic efficiency of laccase and the Cu/GMP MOFzyme to oxidize four substrates. (B) A scheme of oxidizing epinephrine and photographs of the product in MES buffer after 20 min reaction. (C) UV-vis spectra of epinephrine and its oxidation product by the MOFzyme. (D) The kinetics of oxidization of epinephrine $(50 \mu \mathrm{g} / \mathrm{mL})$ in the presence of $0.1 \mathrm{mg} / \mathrm{mL}$ of laccase or Cu/GMP MOFzyme. (E) Photographs of visible detection of different concentrations $(5-50 \mu \mathrm{g} / \mathrm{mL})$ of epinephrine. $(\mathrm{F})$ Linear relationships between the absorbance at $485 \mathrm{~nm}$ and the concentration of epinephrine in the presence of laccase and the MOFzyme.

The colored product of this reaction might be used as a way of measuring epinephrine. To test this, we monitored the absorbance of the product as a function of epinephrine concentration in the presence of the same mass concentration of enzymes (Figure 7E, F). The detection limit of epinephrine is $0.41 \mu \mathrm{g} / \mathrm{mL}$ in the presence of $\mathrm{Cu} / \mathrm{GMP}$, while $6.67 \mu \mathrm{g} / \mathrm{mL}$ in the presence of enzyme. Therefore, $\mathrm{Cu} / \mathrm{GMP}$ is about 16 times more sensitive. The price of commercial laccase is 150 -fold higher than that of GMP. Therefore, to achieve the same 
conversion rate of epinephrine, the Cu/GMP MOF is $~ 2400$-fold more cost-effective (the cost of $\mathrm{Cu}^{2+}$ is negligible).

To use such nanozymes to replace protein laccases in industrial catalysis still has a long way to go. For example, nanozymes in general has not achieved good substrate selectivity, which is a hallmark of enzymes. Future developments are also expected for immobilization of nanozymes so that they can be recycled and purified away from the product. With a much lower cost and good reproducibility, nanozymes are likely to replace protein enzymes for certain applications in future.

\section{Conclusions}

In summary, we demonstrated an extraordinarily simple yet highly active and robust laccase mimic based on GMP coordinated $\mathrm{Cu}^{2+}$. $\mathrm{Cu} / \mathrm{GMP}$ forms an amorphous MOF with laccase-like activity. Natural laccases are multi-copper metalloenzymes and the Cu/GMP complex is a good functional mimic. With more structural information, it may even be proven to be a structural mimic given the multi-copper nature of $\mathrm{Cu} / \mathrm{GMP}$. Compared to the protein laccase, $\mathrm{Cu} / \mathrm{GMP}$ is much more robust against extreme $\mathrm{pH}$, temperature, salt and long-term storage. It also converts a diverse range of substrates just like laccase. At the same mass concentration, $\mathrm{Cu} / \mathrm{GMP}$ has even a higher catalytic rate with most substrates. The preparation of $\mathrm{Cu} / \mathrm{GMP}$ is very simple with a mixing of two common chemicals at room temperature. This material will likely find important applications to replace the role of laccase in analytical chemistry, environmental remediation, and biotechnology. At the same time, it provides an interesting model system for studying multi-copper laccases. 


\section{Acknowledgement}

The authors acknowledge financial support from the Beijing Natural Science Foundation (2162030), the Fundamental Research Funds for the Central Universities (YS1407), China Scholarship Council, the 111 project, and the Natural Sciences and Engineering Research Council of Canada (NSERC).

\section{Supporting Information}

The Supporting Information is available free of charge on the ACS Publications website at DOI: $10.1021 /$ acsami

UV-vis absorbance of $\mathrm{Cu} /$ nucleotide MOFs; the yield and activity of GMP mixed with various concentration of $\mathrm{Cu}^{2+}$; particle sizes and $\zeta$-potential; full scan XPS spectra; FTIR and $\mathrm{XRD}$ analysis; TEM images of $\mathrm{Cu} / \mathrm{GMP}$ at different conditions; the chemical structures of four phenols; the Lineweaver-Burk curve and kinetic parameters of $\mathrm{Cu} / \mathrm{GMP}$ and Laccase. (PDF)

\section{References:}

1. Galli, C.; Madzak, C.; Vadalà, R.; Jolivalt, C.; Gentili, P., Concerted Electron/Proton Transfer Mechanism in the Oxidation of Phenols by Laccase. ChemBioChem 2013, 14 (18), 2500-2505.

2. Jones, S. M.; Solomon, E. I., Electron Transfer and Reaction Mechanism of Laccases. Cell. Mol. Life Sci. 2015, 72 (5), 869-883.

3. Mate, D. M.; Alcalde, M., Laccase Engineering: From Rational Design to Directed 
Evolution. Biotechnol. Adv. 2015, 33 (1), 25-40.

4. Tanaka, Y.; Hoshino, W.; Shimizu, S.; Youfu, K.; Aratani, N.; Maruyama, N.; Fujita, S.; Osuka, A., Thermal Splitting of Bis-Cu(II) Octaphyrin(1.1.1.1.1.1.1.1) into Two $\mathrm{Cu}(\mathrm{II})$ Porphyrins. J. Am. Chem. Soc. 2004, 126 (10), 3046-3047.

5. Verónica Rivas, M.; Méndez De Leo, L. P.; Hamer, M.; Carballo, R.; Williams, F. J., Self-Assembled Monolayers of Disulfide Cu Porphyrins on Au Surfaces: Adsorption Induced Reduction and Demetalation. Langmuir 2011, 27 (17), 10714-10721.

6. Uhlmann, C.; Swart, I.; Repp, J., Controlling the Orbital Sequence in Individual Cu-Phthalocyanine Molecules. Nano Lett. 2013, 13 (2), 777-780.

7. Eyele-Mezui, S.; Vialat, P.; Higy, C.; Bourzami, R.; Leuvrey, C.; Parizel, N.; Turek, P.; Rabu, P.; Rogez, G.; Mousty, C., Electrocatalytic Properties of Metal Phthalocyanine Tetrasulfonate Intercalated in Metal Layered Simple Hydroxides (Metal: Co, Cu, and Zn). J. Phys. Chem. C 2015, 119 (23), 13335-13342.

8. Thorseth, M. A.; Tornow, C. E.; Tse, E. C. M.; Gewirth, A. A., Cu Complexes that Catalyze the Oxygen Reduction Reaction. Coord. Chem. Rev. 2013, 257 (1), 130-139.

9. Zhou, L.; Powell, D.; Nicholas, K. M., Tripodal Bis(imidazole) Thioether Copper(I) Complexes: Mimics of the $\mathrm{Cu}(\mathrm{B})$ Site of Hydroxylase Enzymes. Inorg. Chem. 2006, 45 (10), 3840-3842.

10. Zhou, L.; Nicholas, K. M., Imidazole Substituent Effects on Oxidative Reactivity of Tripodal(imid)2(thioether)CuI Complexes. Inorg. Chem. 2008, 47 (10), 4356-4367.

11. Nastri, F.; Chino, M.; Maglio, O.; Bhagi-Damodaran, A.; Lu, Y.; Lombardi, A., Design and Engineering of Artificial Oxygen-Activating Metalloenzymes. Chem. Soc. Rev. 2016, 
45 (18), 5020-5054.

12. Wei, H.; Wang, E., Nanomaterials with Enzyme-like Characteristics (Nanozymes): Next-generation Artificial Enzymes. Chem. Soc. Rev. 2013, 42 (14), 6060-6093.

13. Cheng, H.; Zhang, L.; He, J.; Guo, W.; Zhou, Z.; Zhang, X.; Nie, S.; Wei, H., Integrated Nanozymes with Nanoscale Proximity for in vivo Neurochemical Monitoring in Living Brains. Anal. Chem. 2016, 88 (10), 5489-5497.

14. Wang, X.; Hu, Y.; Wei, H., Nanozymes in Bionanotechnology: From Sensing to Therapeutics and Beyond. Inorg. Chem. Front. 2016, 3 (1), 41-60.

15. Comotti, M.; Della Pina, C.; Matarrese, R.; Rossi, M., The Catalytic Activity of "Naked" Gold Particles. Angew. Chem., Int. Ed. 2004, 43 (43), 5812-5815.

16. Jv, Y.; Li, B.; Cao, R., Positively-charged Gold Nanoparticles as Peroxidiase Mimic and their Application in Hydrogen Peroxide and Glucose Detection. Chem. Commun. 2010, 46 (42), 8017-8019.

17. Long, Y. J.; Li, Y. F.; Liu, Y.; Zheng, J. J.; Tang, J.; Huang, C. Z., Visual Observation of the Mercury-stimulated Peroxidase Mimetic Activity of Gold Nanoparticles. Chem. Commun. 2011, 47 (43), 11939-11941.

18. Luo, W.; Zhu, C.; Su, S.; Li, D.; He, Y.; Huang, Q.; Fan, C., Self-Catalyzed, Self-Limiting Growth of Glucose Oxidase-Mimicking Gold Nanoparticles. ACS Nano 2010, 4 (12), 7451-7458.

19. Liu, B.; Sun, Z.; Huang, P.-J. J.; Liu, J., Hydrogen Peroxide Displacing DNA from Nanoceria: Mechanism and Detection of Glucose in Serum. J. Am. Chem. Soc. 2015, 137 (3), 1290-1295. 
20. Liu, B.; Huang, Z.; Liu, J., Boosting the Oxidase Mimicking Activity of Nanoceria by Fluoride Capping: Rivaling Protein Enzymes and Ultrasensitive $\mathrm{F}^{-}$Detection. Nanoscale 2016, 8 (28), 13562-13567.

21. Liu, B.; Han, X.; Liu, J., Iron Oxide Nanozyme Catalyzed Synthesis of Fluorescent Polydopamine for Light-up $\mathrm{Zn}^{2+}$ Detection. Nanoscale 2016, 8 (28), 13620-13626.

22. Liu, B.; Liu, J., Accelerating Peroxidase Mimicking Nanozymes Using DNA. Nanoscale 2015, 7 (33), 13831-13835.

23. Gao, L.; Zhuang, J.; Nie, L.; Zhang, J.; Zhang, Y.; Gu, N.; Wang, T.; Feng, J.; Yang, D.; Perrett, S.; Yan, X., Intrinsic Peroxidase-like Activity of Ferromagnetic Nanoparticles. Nat. Nanotechnol. 2007, 2 (9), 577-583.

24. Chen, Z.; Yin, J.-J.; Zhou, Y.-T.; Zhang, Y.; Song, L.; Song, M.; Hu, S.; Gu, N., Dual Enzyme-like Activities of Iron Oxide Nanoparticles and Their Implication for Diminishing Cytotoxicity. ACS Nano 2012, 6 (5), 4001-4012.

25. Liang, H.; Liu, B.; Yuan, Q.; Liu, J., Magnetic Iron Oxide Nanoparticle Seeded Growth of Nucleotide Coordinated Polymers. ACS Appl. Mater. Interfaces 2016, 8 (24), $15615-15622$.

26. Ren, X.; Liu, J.; Ren, J.; Tang, F.; Meng, X., One-pot Synthesis of Active Copper-containing Carbon Dots with Laccase-like Activities. Nanoscale 2015, 7 (46), 19641-19646.

27. Furukawa, H.; Cordova, K. E.; O’Keeffe, M.; Yaghi, O. M., The Chemistry and Applications of Metal-Organic Frameworks. Science 2013, 341 (6149), 123044.

28. Kitagawa, S.; Kitaura, R.; Noro, S.-i., Functional Porous Coordination Polymers. Angew. 
Chem. Int. Ed. 2004, 43 (18), 2334-2375.

29. Li, J.-R.; Sculley, J.; Zhou, H.-C., Metal-Organic Frameworks for Separations. Chem. Rev. 2012, 112 (2), 869-932.

30. He, L.; Liu, Y.; Liu, J.; Xiong, Y.; Zheng, J.; Liu, Y.; Tang, Z., Core-Shell Noble-Metal@Metal-Organic-Framework Nanoparticles with Highly Selective Sensing Property. Angew. Chem. Int. Ed. 2013, 52 (13), 3741-3745.

31. Bennett, T. D.; Cheetham, A. K., Amorphous Metal-Organic Frameworks. Acc. Chem. Res. 2014, 47 (5), 1555-1562.

32. Nath, I.; Chakraborty, J.; Verpoort, F., Metal Organic Frameworks Mimicking Natural Enzymes: A Structural and Functional Analogy. Chem. Soc. Rev. 2016, 45 (15), 4127-4170.

33. Wiester, M. J.; Ulmann, P. A.; Mirkin, C. A., Enzyme Mimics Based Upon Supramolecular Coordination Chemistry. Angew. Chem. Int. Ed. 2011, 50 (1), 114-137.

34. Larsen, R. W.; Wojtas, L.; Perman, J.; Musselman, R. L.; Zaworotko, M. J.; Vetromile, C. M., Mimicking Heme Enzymes in the Solid State: Metal-Organic Materials with Selectively Encapsulated Heme. J. Am. Chem. Soc. 2011, 133 (27), 10356-10359.

35. Li, B.; Chen, D.; Wang, J.; Yan, Z.; Jiang, L.; Deliang, D.; He, J.; Luo, Z.; Zhang, J.; Yuan, F., MOFzyme: Intrinsic Protease-like Activity of Cu-MOF. Sci. Rep. 2014, 4, 6759.

36. Zheng, J.; Wu, Y.; Deng, K.; He, M.; He, L.; Cao, J.; Zhang, X.; Liu, Y.; Li, S.; Tang, Z., Chirality-Discriminated Conductivity of Metal-Amino Acid Biocoordination Polymer Nanowires. ACS Nano 2016, 10 (9), 8564-8570. 
37. Zhao, M.; Deng, K.; He, L.; Liu, Y.; Li, G.; Zhao, H.; Tang, Z., Core-Shell Palladium Nanoparticle@Metal-Organic Frameworks as Multifunctional Catalysts for Cascade Reactions. J. Am. Chem. Soc. 2014, 136 (5), 1738-1741.

38. Li, C.; Deng, K.; Tang, Z.; Jiang, L., Twisted Metal-Amino Acid Nanobelts: Chirality Transcription from Molecules to Frameworks. J. Am. Chem. Soc. 2010, 132 (23), 8202-8209.

39. Yu, H.; Zhang, S.; Dunn, M. R.; Chaput, J. C., An Efficient and Faithful in vitro Replication System for Threose Nucleic Acid. J. Am. Chem. Soc. 2013, 135 (9), $3583-3591$.

40. Bazzicalupi, C.; Bencini, A.; Lippolis, V., Tailoring Cyclic Polyamines for Inorganic/Organic Phosphate Binding. Chem. Soc. Rev. 2010, 39 (10), 3709-3728.

41. Ruiz-Mirazo, K.; Briones, C.; de la Escosura, A., Prebiotic Systems Chemistry: New Perspectives for the Origins of Life. Chem. Rev. 2014, 114 (1), 285-366.

42. Zhou, P.; Shi, R.; Yao, J.-f.; Sheng, C.-f.; Li, H., Supramolecular Self-assembly of Nucleotide-metal Coordination Complexes: From Simple Molecules to Nanomaterials. Coord. Chem. Rev. 2015, 292, 107-143.

43. Liu, Y.; Tang, Z., Nanoscale Biocoordination Polymers: Novel Materials from an Old Topic. Chem.-Eur. J. 2012, 18 (4), 1030-1037.

44. An, J.; Geib, S. J.; Rosi, N. L., Cation-Triggered Drug Release from a Porous Zinc-Adeninate Metal-Organic Framework. J. Am. Chem. Soc. 2009, 131 (24), 8376-8377.

45. Nishiyabu, R.; Hashimoto, N.; Cho, T.; Watanabe, K.; Yasunaga, T.; Endo, A.; Kaneko, 
K.; Niidome, T.; Murata, M.; Adachi, C.; Katayama, Y.; Hashizume, M.; Kimizuka, N., Nanoparticles of Adaptive Supramolecular Networks Self-Assembled from Nucleotides and Lanthanide Ions. J. Am. Chem. Soc. 2009, 131 (6), 2151-2158.

46. Wang, F.; Liu, B.; Huang, P.-J. J.; Liu, J., Rationally Designed Nucleobase and Nucleotide Coordinated Nanoparticles for Selective DNA Adsorption and Detection. Anal. Chem. 2013, 85 (24), 12144-12151.

47. Wei, H.; Li, B.; Du, Y.; Dong, S.; Wang, E., Nucleobase-Metal Hybrid Materials: Preparation of Submicrometer-Scale, Spherical Colloidal Particles of Adenine-Gold(III) via a Supramolecular Hierarchical Self-Assembly Approach. Chem. Mater. 2007, 19 (12), 2987-2993.

48. Purohit, C. S.; Verma, S., A Luminescent Silver-Adenine Metallamacrocyclic Quartet. J. Am. Chem. Soc. 2006, 128 (2), 400-401.

49. Sukul, P. K.; Malik, S., Supramolecular Hydrogels of Adenine: Morphological, Structural and Rheological Investigations. Soft Matter 2011, 7 (9), 4234-4241.

50. Liang, H.; Zhang, Z.; Yuan, Q.; Liu, J., Self-healing Metal-coordinated Hydrogels using Nucleotide ligands. Chem. Commun. 2015, 51 (82), 15196-15199.

51. Liang, H.; Jiang, S.; Yuan, Q.; Li, G.; Wang, F.; Zhang, Z.; Liu, J., Co-immobilization of Multiple Enzymes by Metal Coordinated Nucleotide Hydrogel Nanofibers: Improved Stability and an Enzyme Cascade for Glucose Detection. Nanoscale 2016, 8 (11), 6071-6078.

52. Marino, N.; Armentano, D.; Pardo, E.; Vallejo, J.; Neve, F.; Di Donna, L.; De Munno, G., Homochiral Self-assembly of Biocoordination Polymers: Anion-triggered Helicity and 
Absolute Configuration Inversion. Chem. Sci. 2015, 6 (7), 4300-4305.

53. Zhou, P.; Yao, J.-f.; Sheng, C.-f.; Li, H., A Continuing Tale of Chirality: Metal Coordination Extended Axial Chirality of 4,4'-Bipy to 1D Infinite Chain under Cooperation of a Nucleotide Ligand. CrystEngComm 2013, 15 (42), 8430-8436.

54. Zhou, P.; Li, H., Chirality Delivery from A Chiral Copper(II) Nucleotide Complex Molecule to its Supramolecular Architecture. Dalton Trans. 2011, 40 (18), 4834-4837.

55. Ge, J.; Lei, J.; Zare, R. N., Protein-inorganic Hybrid Nanoflowers. Nat. Nanotechnol. 2012, 7 (7), 428-432.

56. Lopez, A.; Liu, J., Light-Activated Metal-Coordinated Supramolecular Complexes with Charge-Directed Self-Assembly. J. Phys. Chem. C 2013, 117 (7), 3653-3661.

57. Liu, P.; Hensen, E. J. M., Highly Efficient and Robust $\mathrm{Au} / \mathrm{MgCuCr}_{2} \mathrm{O}_{4}$ Catalyst for Gas-Phase Oxidation of Ethanol to Acetaldehyde. J. Am. Chem. Soc. 2013, 135 (38), 14032-14035.

58. Platzman, I.; Brener, R.; Haick, H.; Tannenbaum, R., Oxidation of Polycrystalline Copper Thin Films at Ambient Conditions. J. Phys. Chem. C 2008, 112 (4), 1101-1108.

59. Zhang, Y.; Ge, J.; Liu, Z., Enhanced Activity of Immobilized or Chemically Modified Enzymes. ACS Catal. 2015, 5 (8), 4503-4513.

60. Wu, X.; Ge, J.; Yang, C.; Hou, M.; Liu, Z., Facile Synthesis of Multiple Enzyme-containing Metal-organic Frameworks in a Biomolecule-friendly Environment. Chem. Commun. 2015, 51 (69), 13408-13411. 